\title{
Calibrating historical IR sensors using GEO and AVHRR infrared tropical mean calibration models
}

Benjamin Scarino*a, David R. Doelling ${ }^{\mathrm{b}}$, Patrick Minnis ${ }^{\mathrm{b}}$, Arun Gopalan ${ }^{\mathrm{a}}$, Conor Haney ${ }^{\mathrm{a}}$, Rajendra Bhatt $^{\mathrm{a}}$

${ }^{a}$ SSAI, One Enterprise Pkwy Ste 200, Hampton, VA 23666 USA

bNASA Langley Research Center, 21 Langley Blvd MS 420, Hampton, VA 23681-2199 USA

\begin{abstract}
Long-term, remote-sensing-based climate data records (CDRs) are highly dependent on having consistent, wellcalibrated satellite instrument measurements of the Earth's radiant energy. Therefore, by making historical satellite calibrations consistent with those of today's imagers, the Earth-observing community can benefit from a CDR that spans a minimum of 30 years. Most operational meteorological satellites rely on an onboard blackbody and space looks to provide on-orbit IR calibration, but neither target is traceable to absolute standards. The IR channels can also be affected by ice on the detector window, angle dependency of the scan mirror emissivity, stray-light, and detector-to-detector striping. Being able to quantify and correct such degradations would mean IR data from any satellite imager could contribute to a CDR. Recent efforts have focused on utilizing well-calibrated modern hyper-spectral sensors to intercalibrate concurrent operational IR imagers to a single reference. In order to consistently calibrate both historical and current IR imagers to the same reference, however, another strategy is needed. Large, well-characterized tropical-domain Earth targets have the potential of providing an Earth-view reference accuracy of within $0.5 \mathrm{~K}$. To that effort, NASA Langley is developing an IR tropical mean calibration model in order to calibrate historical Advanced Very High Resolution Radiometer (AVHRR) instruments. Using Meteosat-9 (Met-9) as a reference, empirical models are built based on spatially/temporally binned Met-9 and AVHRR tropical IR brightness temperatures. By demonstrating the stability of the Met-9 tropical models, NOAA-18 AVHRR can be calibrated to Met-9 by matching the AVHRR monthly histogram averages with the Met-9 model. This method is validated with ray-matched AVHRR and Met-9 biasdifference time series. Establishing the validity of this empirical model will allow for the calibration of historical AVHRR sensors to within $0.5 \mathrm{~K}$, and thereby establish a climate-quality IR data record.
\end{abstract}

Keywords: Meteosat-9, AVHRR, radiometric calibration, infrared, histogram matching, cumulative distribution function, invariant Earth targets

\section{INTRODUCTION}

Having consistent and well-calibrated radiances as a fundamental dataset is essential to the development of longterm satellite-based climate data records (CDR). Varieties of satellites have borne and currently carry imaging radiometers with spectral channels that are often similar in wavelength ranges, but differ in response characteristics and calibrations. Once properly calibrated, data from any satellite imager could contribute to the development of long-term CDRs of quantities useful for monitoring changes in climate. Most operational meteorological satellites have onboard calibration systems for their infrared channels, however even with onboard calibration systems, the infrared calibrations typically suffer from other factors that disturb or degrade the quality of the output radiances. Correcting for such degradations is made difficult for lack of single-reference standards.

The need for consistent calibration coefficients across space-based sensors - tied to an absolute calibration reference - led to the development of the WMO Global Space-based Inter-Calibration System (GSICS) ${ }^{1}$. This developing system seeks to correct calibration inconsistencies among various current Geostationary Earth Orbit (GEO) and Low Earth Orbit (LEO) operational satellites. Calibration results for infrared channels on several recent GEO imagers have been developed and are currently online. The GSICS effort utilizes either Infrared Atmospheric Sounding Interferometer (IASI) or Atmospheric Infrared Sounder (AIRS) hyperspectral radiances as the reference for calibrating GEO imager infrared channels ${ }^{2}$. Although each GSICS group is responsible for their country's satellite calibration, the overarching

*benjamin.r.scarino@nasa.gov; $\quad$ phone1757951-1622; $\quad$ fax 1757 951-1902 
goal is to make all of them consistent through some common practices and references. Most of the efforts have been devoted to satellites operating over the past 10 years or less.

Since 1984, NASA Langley has been intercalibrating satellites as a means to utilize satellite imager data in order to study radiation and clouds. A nearly simultaneous ray-matched technique (NSRT) was developed to calibrate 1978 GOES-2 data against a reference LEO sensor in terms of broadband radiation, and against Meteosat-1 data in terms of narrowband radiances ${ }^{3,4}$. Langley also refined the GEO-to-GEO NSRT cross-calibration method using only data taken near local noon or at night (IR only) for the pixels straddling the bisecting longitude between the two satellites ${ }^{5}$. Visible channels on the Terra MODerate-resolution Imaging Spectroradiometer (MODIS), the GOES-8 imager, the Tropical Rainfall Measuring Mission (TRMM) Visible and Infrared Scanner (VIRS), the Japanese Geostationary Meteorological Satellite (GMS), and the second Along-Track Scanning Radiometer (ATSR-2) were also inter-calibrated using the $\mathrm{NSRT}^{6}$. Similarly, the 3.8-, 10.8-, and $12.0-\mu \mathrm{m}$ channels on those same satellites were inter-calibrated using VIRS as a reference ${ }^{7}$. Within those same studies, the well-calibrated TRMM Clouds and the Earth's Radiant Energy System (CERES) broadband shortwave and longwave data were used to monitor the stability in the VIRS visible, 1.6-, 3.8-, $10.8-$, and $12.0-\mu \mathrm{m}$ channels using the NSRT. Minnis et al. performed interconsistency analyses using VIRS, AquaMODIS, and Terra-MODIS along with CERES broadband data, thereby revealing degradation in the VIRS visible channel and discontinuities in the Terra MODIS visible channel ${ }^{8}$. The NSRT and the deep convective cloud (DCC) albedo methods were used in that study to define the time-dependence of the gains in each satellite. MODIS and VIRS data were again inter-calibrated using the NSRT, revealing significant problems in the VIRS 1.6- $\mu \mathrm{m}$ channel and the Terra MODIS 3.8- $\mu \mathrm{m}$ channel $^{9}$.

Before completing those studies, NASA Langley began participating in the GSICS research group and contributing to the GSICS effort. The DCC method was further refined, and a robust desert-site calibration monitoring method was developed $^{10,11,12,13}$. In the past, when Langley used ocean targets only for applying the NSRT, no spectral response function (SRF) difference correction was made based on the assumption that the reflectance should be nearly the same for the various imagers over spectrally flat surfaces such as the ocean. This assumption, however, introduces errors because of variations in Rayleigh scattering, ozone absorption, and other absorption lines having influences that vary from sensor to sensor. To account for these spectral differences, other intercalibration methods use theoretical radiative transfer modeling ${ }^{14}$. Langley has developed a technique that utilizes high-spectral-resolution data from the SCanning Imaging Absorption spectroMeter for Atmospheric CartograpHY (SCIAMACHY) to define the spectral correction factors for any pair of visible spectral response, over any surface type ${ }^{15,16,17,18}$. The results demonstrate that the empirical corrections are highly accurate, thus removing much of the uncertainty associated with theoretical corrections. A similar empirical approach is possible for IR channels using IASI hyper-spectral data.

Consistent calibration among older and current satellites is essential to the development of reliable CDRs. Although IR imagers have onboard blackbodies to maintain stability, a traceable absolute calibration remains necessary. Thus, it is important to extend the satellite records as far into the past as possible by making older satellite calibrations consistent with those of current imagers. Overlapping satellite records can be used to achieve this feat. For example, Knapp et al., used sequential NOAA High-resolution Infrared Radiation Sounder (HIRS) records as the calibration reference for a GEO CDR, and Chen et al. optimized the SRF for each overlapping HIRS to account for inter-satellite radiance discrepancies and generate a more consistent long-term set of observations ${ }^{19,20}$. Additionally, the International Satellite Cloud Climatology Project (ISSCP) used overlapping Advanced Very High Resolution Radiometer (AVHRR) IR measurements to calibrate GEO imager temperatures ${ }^{21}$.

We propose IR pseudo invariant calibration sites (PICS) similar to desert, polar ice, and DCC to monitor the longterm performance of the 1980-to-present AVHRR IR record. There have been past efforts to establish stable IR Earth domains, such as the IR tropical mean studies by Wielicki et al. and Trenberth, to aid in verifying the OLR calibration record of the CERES non-scanner record ${ }^{22,23}$. First, the study finds the most inter-annually stable IR Earth sites using the Terra and Aqua CERES MODIS window channel record. Both warm and cold targets would need to be found because the AVHRR IR calibration accuracy is a function of BT. The Namibian stratus site is selected to demonstrate the PICS concept. The site inter-annual natural variability is described in Section 2.2. Owing to the AVHRR degrading orbits, which are 1:30 PM sun-synchronous orbits that after a few years reside in a near-sunset-terminator condition, the site must be diurnally characterized. The Metoesat-9 geostationary imager scans a full disc every 15 minutes and is well suited to characterize the site diurnally. Section 2.3 validates the IR calibration stability of the 6-year Meteosat-9 record and ties the IR calibration to the IASI absolute calibration. Section 2.4 characterizes the site seasonally and diurnally and establishes the IR PICS model, which can be applied over the AVHRR record. Section 2.5 demonstrates the application 
of the model with the NOAA-18 AVHRR IR record. Section 3 compares the NOAA-18 AVHRR calibration derived from the IR PICS model and with the NSRT method. The results will present an alternative method for IR sensor calibration that can be used historically, which can be validated by comparing the AVHRR BT over time, and which has been inter-calibrated using a well-calibrated IR imager, thereby supporting its use in establishing a climate-quality IR data record.

\section{DATA AND METHODOLOGY}

\subsection{Choosing a Stable Tropical Domain}

Although generally more temporally stable than land regions owing to their inherit immunity to vegetation- and ground-moisture-induce variability, one nevertheless must be selective when choosing a stable tropical IR ocean domain with which to perform calibration studies. Such a region should be outside of areas significantly influenced by major temperature oscillations (e.g., ENSO, AMO), and is ideally unaffected by daily land/sea breeze effects and seasonal tropical cyclones. The search for a stable tropical ocean domain is conducted by analyzing eleven years of CERES Aqua Single Scanner Footprint spatially gridded $1^{\circ}$ by $1^{\circ}$ lat/lon (SSF1deg) observed all-sky top-of-atmosphere (TOA) monthly mean longwave fluxes $(5-100 \mu \mathrm{m})$ (http://ceres.larc.nasa.gov/order_data.php). Figure 1 shows the regional standard deviation of the TOA monthly mean longwave fluxes $\left(\mathrm{Wm}^{-2}\right)$ from 2002 through 2012 . The largest stable region falls within the Namibian ocean stratus region from, $-5^{\circ}$ to $-20^{\circ}$ latitude and $17^{\circ}$ to $0^{\circ}$ longitude. Other suitable sites include the Peruvian ocean stratus region, the Egyptian Desert (warm targets), Greenland, and Dome-C Antarctica (cold targets). The latter three have rather large seasonal and diurnal cycles, however, their long-term inter-annual variability remains small. In this study, the Namibian stratus region is chosen because it is outside the influence of the ITCZ, is relatively unaffected by diurnal land/ocean boundary phenomena, and is sufficiently far enough south of both the tropical cyclone corridor and the Atlantic Multi-decadal Oscillation region - facts that are supported by the CERESSSF-indicated stability ${ }^{24}$. Furthermore, it is well-monitored by the calibrated Met- 9 imager, and thus is a favorable choice for a reference model. Fig. 2 enlarges the defined site.
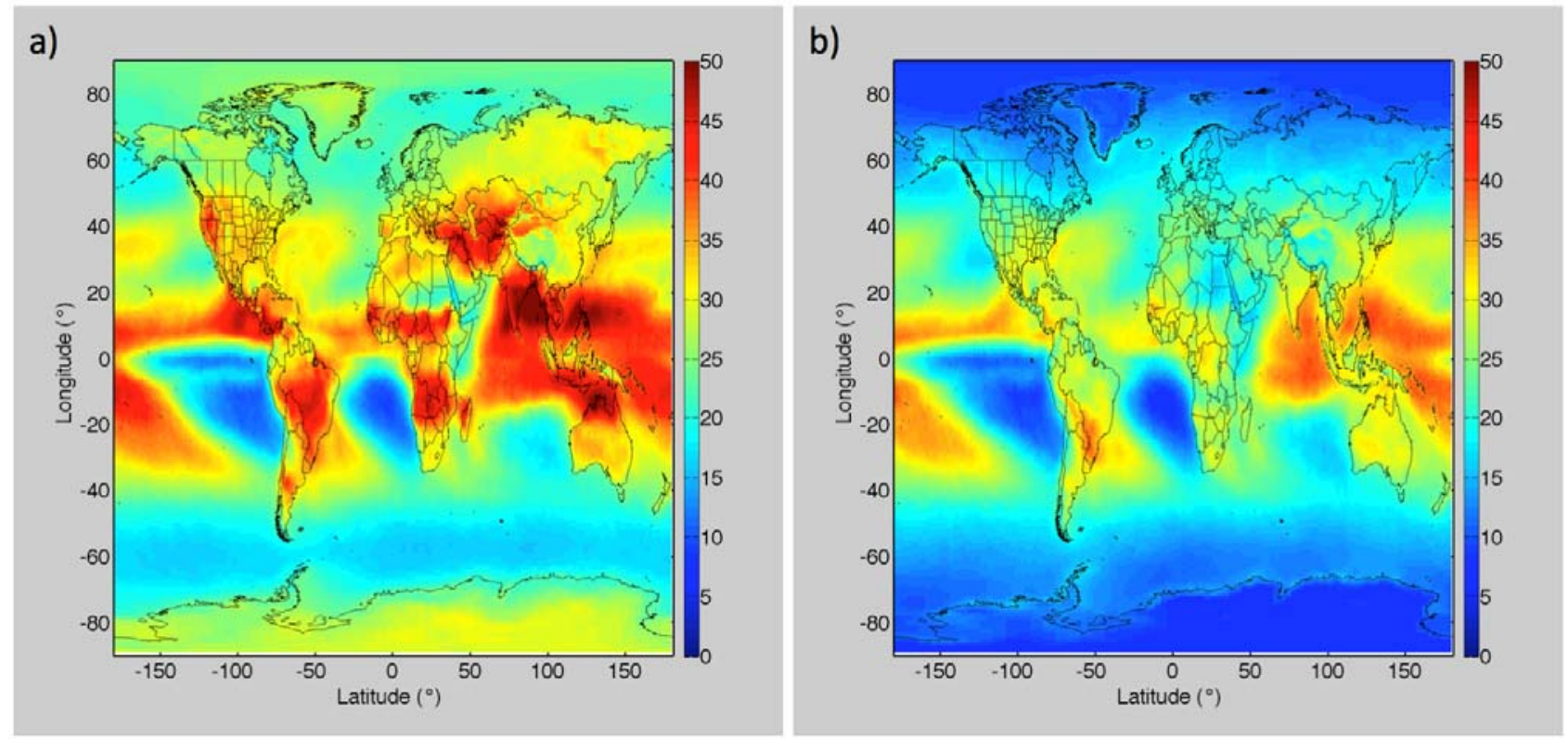

Figure 1. Standard deviation of the monthly mean CERES Aqua spatially gridded $1^{\circ}$ by $1^{\circ}$ lat $/$ lon SSF 1 deg TOA longwave fluxes $\left(\mathrm{Wm}^{-2}\right.$ ) from 2002 through 2012 (a) without and (b) with a deseasonalization adjustment. 

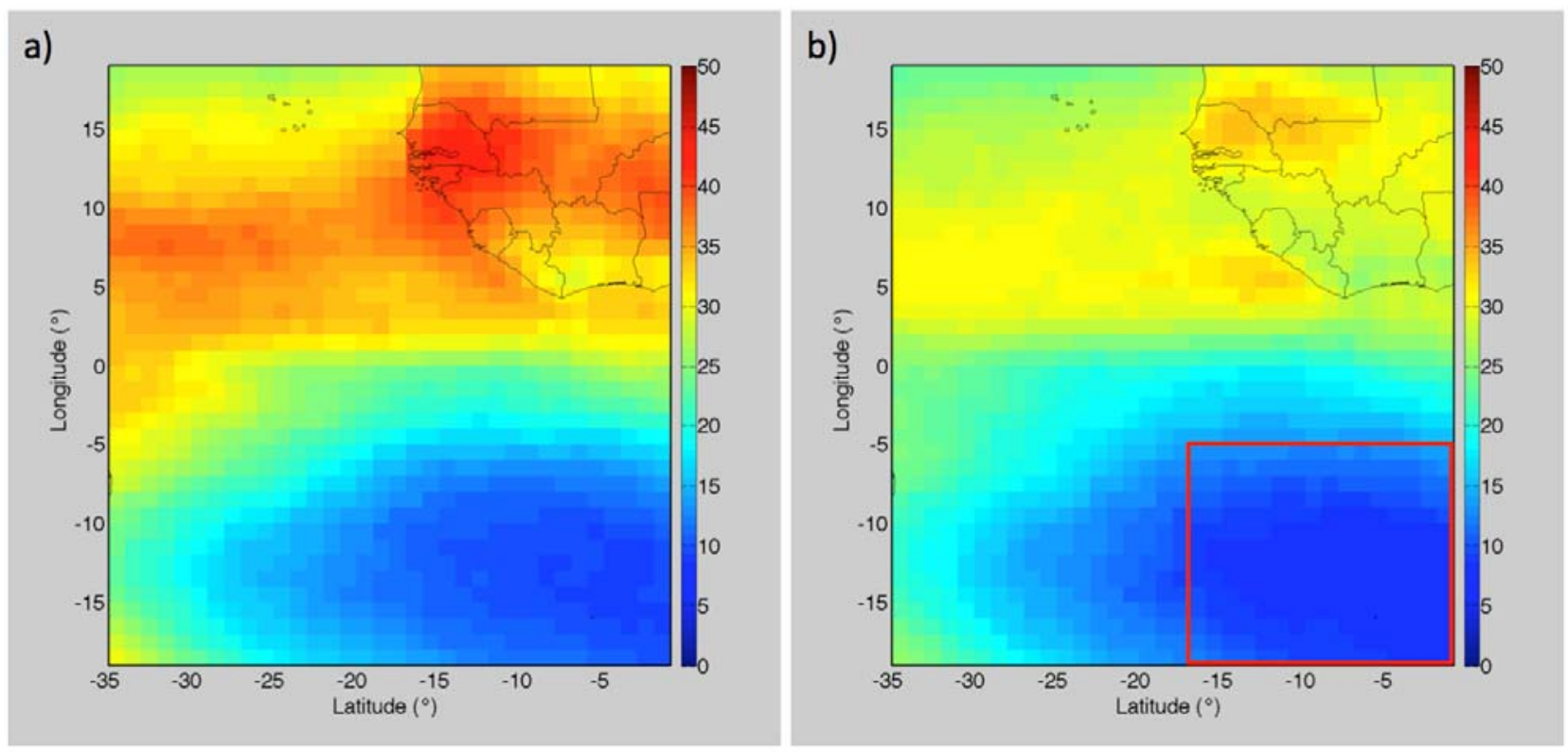

Figure 2. Same as Fig. 1, except with a focus on the Met-9 tropical ocean region. The red box indicates the very stable tropical ocean subdomain (Namibian stratus site) chosen for this study.

\subsection{Site Temporal Natural Variability}

One must consider the natural short-term inter-annual variability unique to each calibration site. In a future study it will be possible to isolate the natural variability of an individual site by comparing it with other sites, which would then allow far calibration of the AVHRR IR record by comparing to the IR target, and then separating any long-term residual that is not part of the known natural variability for that region. For this study, all-sky Terra- and Aqua-CERES SSF1deg monthly gridded $1^{\circ}$ by $1^{\circ}$ lat/lon TOA Window (WN) $(8-12 \mu \mathrm{m}$ bandwidth) monthly means fluxes over the Namibian stratus region are used as a means to track the natural temporal variability of the site. Figure 3 show the 12-month running mean of WN fluxes from CERES Aqua- and Terra-MODIS, from March 2000 through February 2013. The data reveal no discernable long-term trend (verified by Fig. 2). The mean 14-year WN flux over the site is $\sim 83 \mathrm{Wm}^{-2}-$ indicating a natural variability of $\pm 1 \%$.

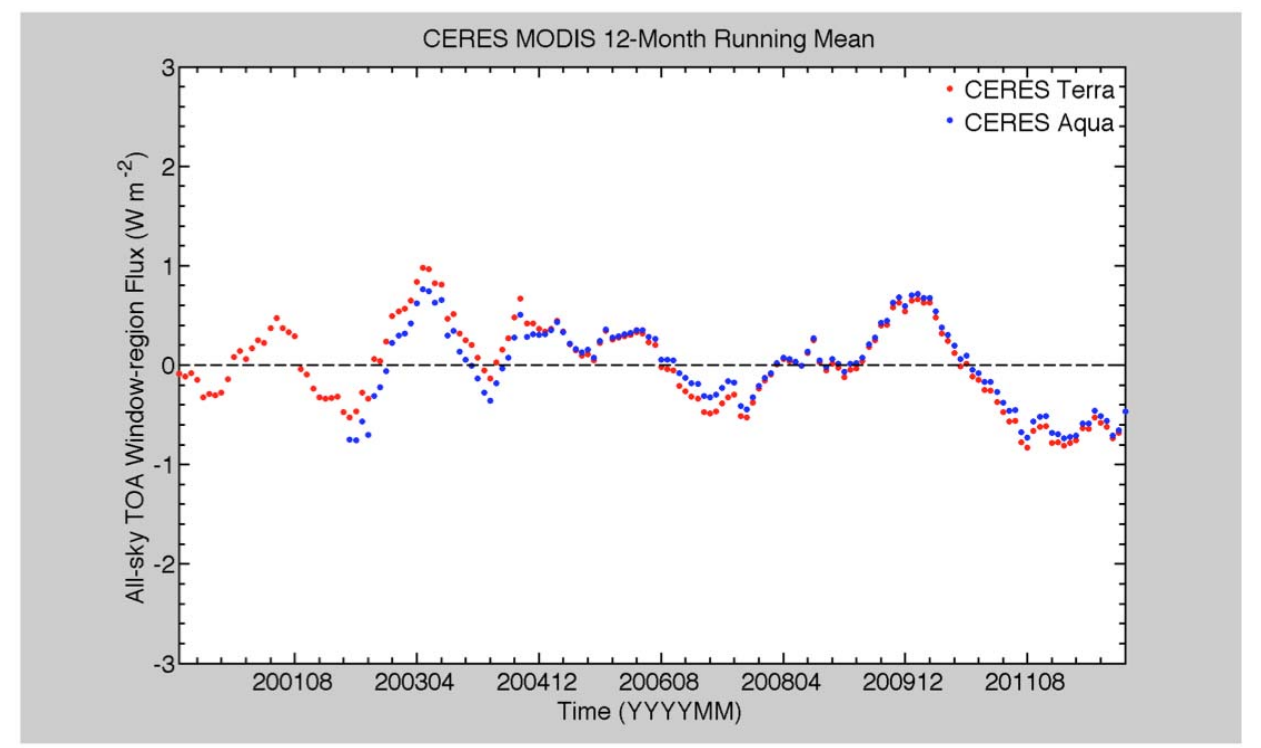

Figure 3. Natural variability of the Namibian stratus region as illustrated by a timeline of 12-month running mean CERES MODIS deseasonalized all-sky TOA WN flux. 


\subsection{Validation of the Met-9 11- $\mu$ m Imager Temporal Stability}

Section 2.1 established the stability of the tropical domain chosen for this study, however, the stability of the reference instrument itself also needs to be verified. Doing so is important because the Namibian stratus site needs to be traceable to well-calibrated IR sensor diurnally, seasonally, and inter-annually, the former of which can only be accomplished with GEO or precessionary satellites. Meteosat-9 serves as an adequate reference not only because of its low-angle view of the calibration target, but also because of its constancy and accuracy compared to other wellcalibrated references. Figure $4 \mathrm{a}$ reveals that the daytime Met-9-minus-Aqua-MODIS temperature bias from monthly NRST analysis is consistently within $\pm 0.5 \mathrm{~K}$ at both $290 \mathrm{~K}$ and $220 \mathrm{~K}$, and remains steady after April 2008. A deicing event took place in April 2008, which is why the calibration transfer model is based on the data from and following May 2008. Furthermore, after applying GSICS correction factors, which are based on IASI hyperspectral radiances, the bias compared to the onboard reference shows no seasonal variation (Fig. 4b). This revelation suggests that the seasonal variability is due to Met-9 and MODIS spectral difference, and that because the Met-9 imager is calibrated to within 0.1 $\mathrm{K}$ of IASI, it needs no further calibration adjustment. Therefore Met-9 is an ideal choice for reference as it is both stable over time (Fig. 4a) and is traceable to IASI (Fig. 4b).

a)

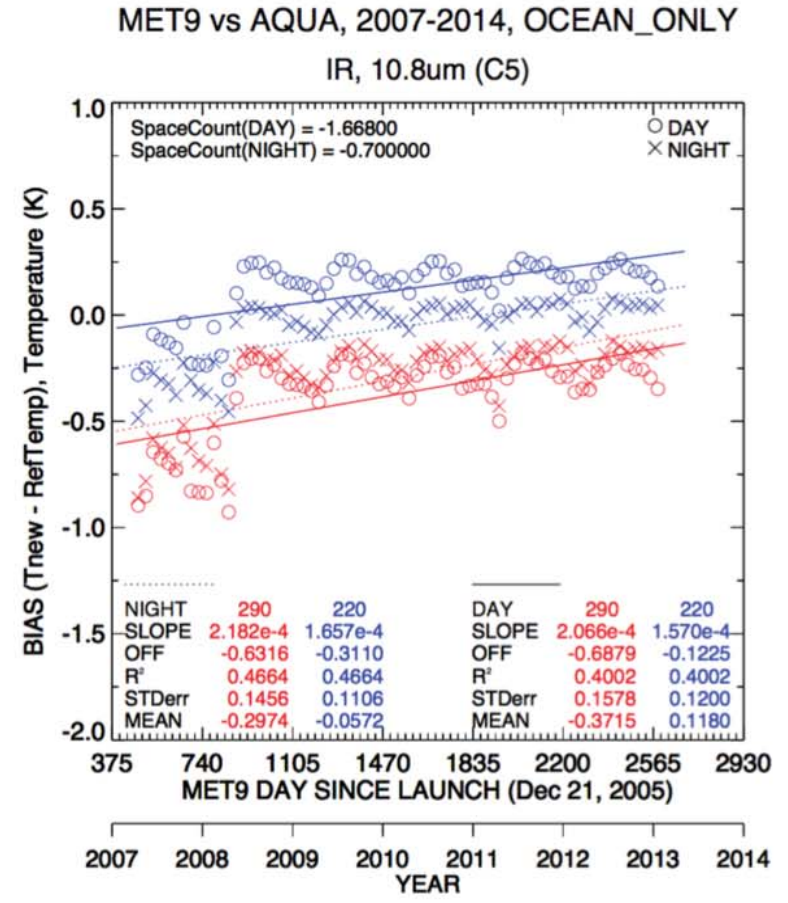

b) MET9 vs GSICS, 2007-2014, OCEAN_ONLY

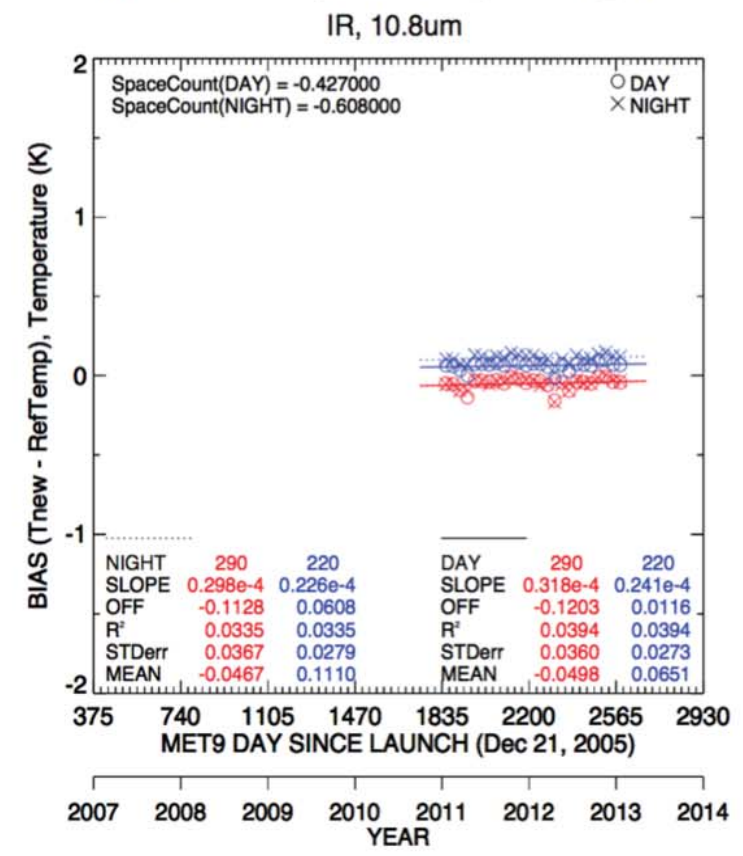

Figure 4. (a) Met-9 and Aqua-MODIS $0.5^{\circ}$ gridded coincident view-angle matched $11-\mu \mathrm{m}$ temperature bias showing the impact of the April 2008 deicing event. (b) Corrected Met-9 temperatures based on GSICS IASI hyperspectral radiance adjustment factors.

\subsection{Site Brightness Temperature Characterization}

Figure 4a shows evidence of a small seasonal dependency. This fact is supported further by the empirical dataset of the model itself (Fig. 5). As the histograms indicate, this Namibian site is primarily a combination of clear-sky ocean and stratus clouds. There is a modal shift in August (not shown) when the primary peak changes from indicating clear-sky dominance to stratus dominance, which then shifts back again in November (not shown). Because of the obvious seasonal dependency and month-specific modal shifts, it is important that the Met-9 calibration transfer model is appropriate for each month. 


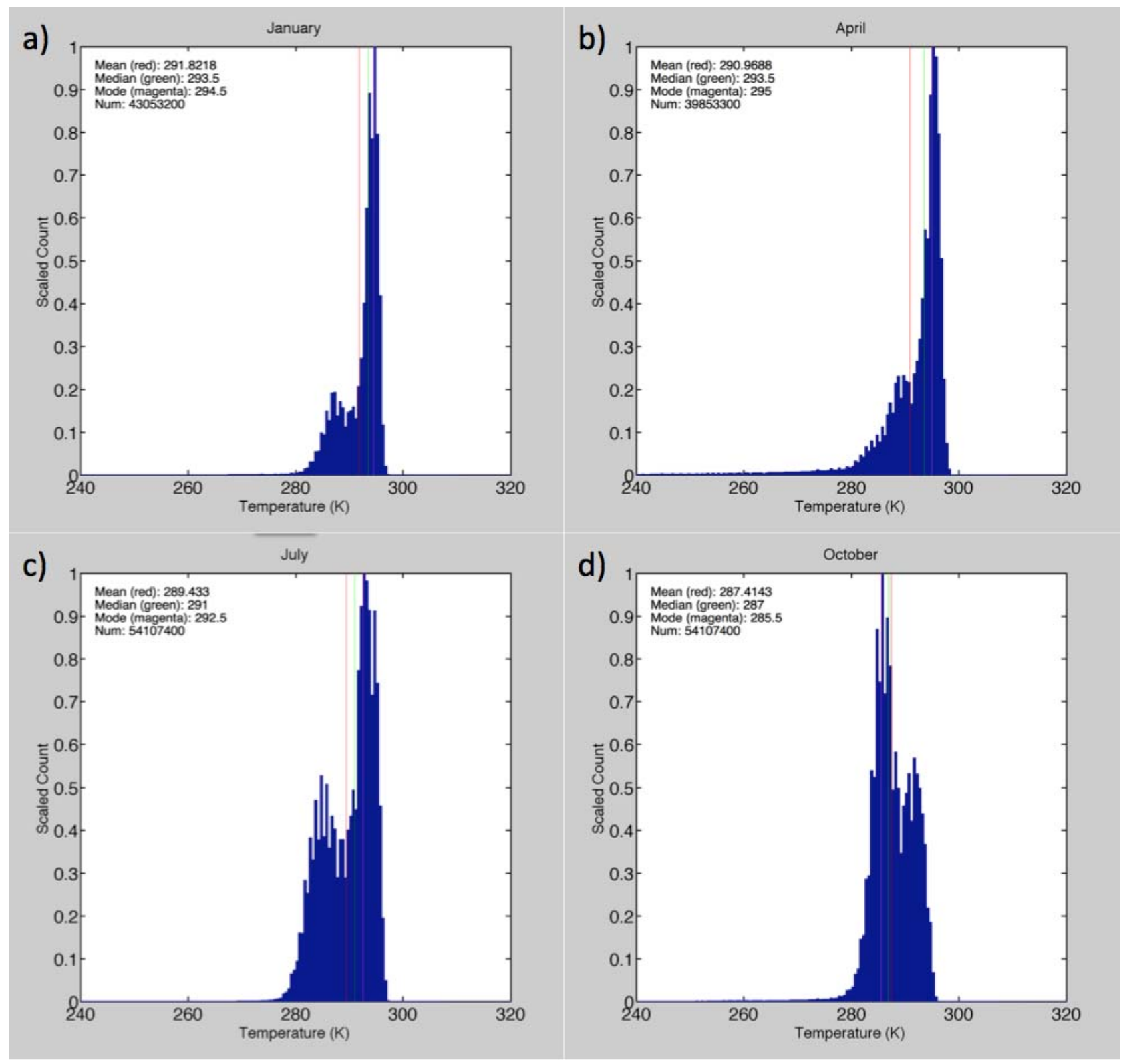

Figure 5. Four seasonal months of 2008 (2009 for (a) and (b)) through 2012, 13:30 - 17:30 UTC PDFs of Met-9 11- $\mu$ m BT.

Because this model can be used to calibrate the afternoon-orbiter instruments, it is important to investigate the hourly stability of Met-9, but this is the beyond the scope of this study. It is known that GOES satellites may have midnight IR calibration biases, but this should not be a factor during the afternoon ${ }^{33}$. As LEO satellite orbits degrade, their equatorial crossing time drifts closer and closer to the terminator hour. Therefore, for this model to be useful, Met-9 must be able to remain an effective reference as the LEO orbit drifts. Figure 6 confirms that the seasonal cycle (more than 5-K variation) is much greater than the inter-hourly difference from 13:30 to 17:30 UTC (less than 0.5-K variation). Also evident is that fact that the inter-annual variability (dotted lines) is greatest $(\sim 2 \mathrm{~K})$ during January-June, but is $\sim 1 \mathrm{~K}$ or less during July-December. The BT uncertainty of the model is therefore dependent on month. Additionally, although the hourly dependency is less than $0.5 \mathrm{~K}$, it does appear to be systematic, and therefore diurnal considerations much be taken into account. In this particular study, the model does not yet incorporate diurnal considerations given that uncertainty there is comparable to the model resolution, but nevertheless would be served better by their inclusion. Most importantly, in order for this BT model to be applicable elsewhere, such as at the aforementioned warm and cold sites with strong diurnal variations, it must be both seasonally and diurnally dependent. 

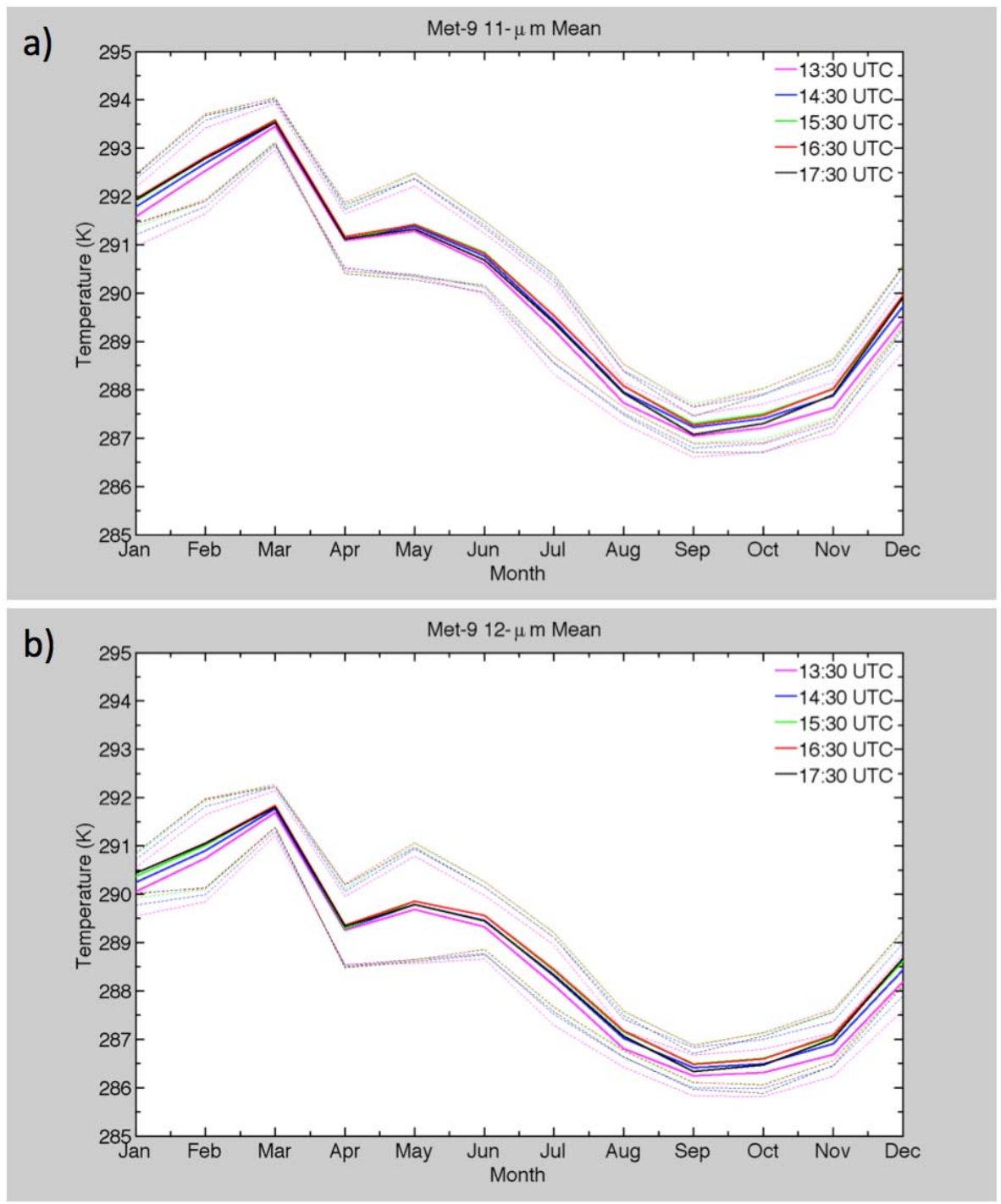

Figure 6. Monthly mean of combined Met-9 May 2008 through December 2012 BT for 13:30, 14:30, 15:30, 16:30, and 17:30 UTC (solid lines), and the 2008 through 2012 standard deviations of those hourly monthly means (dotted lines) for the Met-9 (a) 11- and (b) 12- $\mu \mathrm{m}$ channels.

\subsection{Infrared Model Application}

A histogram matching, or equalization, technique is used to adjust the uncalibrated target data to the reference dataset. The previous section (2.1) describes how such a region was chosen for our Met-9 reference. The histogram matching approach has been employed successfully in numerous satellite de-striping applications ${ }^{25,28,29,30}$. The chosen reference must be stable in time, and must be large such that, on average, each detector experiences roughly equal incident energy $25,26,27,28$. The method has also been successfully applied for satellite visible and IR imager intercalibration purposes, which these proceedings expand upon ${ }^{31,32}$.

As described by Rakwatin et al., the histogram equalization technique involves the matching of the cumulative distribution functions (CDF) of each target instrument (AVHRR in these proceedings) to a reference (Met-9 ${ }^{25}$. For our purposes, the CDF describes the probability that an instrument-output BT, as part of a normal probability distribution, will be found to have a value less than or equal to some BT that is a part of that distribution, given the mean of the distribution and a standard deviation of $1 \mathrm{~K}$. Under those criteria, a CDF of pixel TOA IR BT values is created for each $1^{\circ} \mathrm{x} 1^{\circ}$ grid cell in the stable tropical ocean subdomain for Met-9 and NOAA-18 AVHRR. The NOAA-18 AVHRR instrument is chosen given that its SRF is nearly identical to that of Met-9, obviating the need for spectral adjustment. 
The bin width for each histogram is $0.5 \mathrm{~K}$. For Met-9, the CDFs are comprised of combined monthly data from the entire domain, from May 2008 through December 2012. These CDFs can optionally be stratified into 1-hour increments from 13:30 UTC to 17:30 UTC, which allows for the monitoring of afternoon stability and provides observations of hourly temperature changes corresponding to the orbit-induced degradation of NOAA-18 AVHRR. Histograms for AVHRR are calculated both with and without hourly stratification, with all months combined from January 2006 through December 2012, however, hourly stratification is unnecessary if the reference is shown to be stable throughout the afternoon. The CDF mean, median, and mode statistics are calculated for each histogram.

Histogram matching is achieved by adjusting the AVHRR CDF by bin increments such that the mean histogram temperature is within $0.5 \mathrm{~K}$ of the Met- 9 mean temperature. Because of the $0.5-\mathrm{K}$ histogram resolution, no improvement can be gained when mean differences are already within $\pm 0.5 \mathrm{~K}$, and thus no matching is performed in such cases. Therefore, the accuracy of this IR invariant approach is at best $0.5 \mathrm{~K}$, and will be degraded by the natural variability of the site. Matching is performed for every month of AVHRR data from January 2006 through December 2012. The Met-9 data are averaged on a monthly basis for all years and afternoon hours given the high temporal and annual stability of the sensor (Section 2.3), and the decadal stability of the region (Section 2.1).

The calibration of the Met-9 IR model is transferred to NOAA-18 AVHRR by simply shifting the AVHRR CDF by 0.5-K intervals to best match the Met-9 CDF. NOAA-18 AVHRR CDFs consist of cumulative monthly IR domain BT values from 2006 through 2012, limited to a 5-30 VZA range, which matches the view angle range used by Met-9 to observe the stable tropical domain. The importance of constraining the AVHRR VZA range this way is made evident by Fig. 7, which reveals rather significant limb darkening effects for views exceeding $\sim 35^{\circ}$. Without the VZA constraint, AVHRR ends of up being unrealistically colder than Met-9 given the greater atmospheric path length the AVHRR measurements must travel at high angles compared to Met-9. Figure 8b (solid black curve) shows an example of a VZAconstrained AVHRR 11- $\mu$ m-channel CDF for February 2010, and the Met-9 reference it should match (Fig. 8a). The solid red, green, and magenta lines of Fig. $8 \mathrm{~b}$ are the CDF mean, median, and mode, respectively. The dashed black curve shows the new matched CDF based on Met-9, with corresponding dashed colored lines to show the new mean, median, and mode values. The mean difference between the 11- $\mu \mathrm{m}$ AVHRR CDF and the Met-9 calibration model reduces from $0.61 \mathrm{~K}$ to $0.11 \mathrm{~K}$, from before to after application of the histogram matching. Furthermore, the new AVHRR median and mode values match those of Met-9 after the shift.

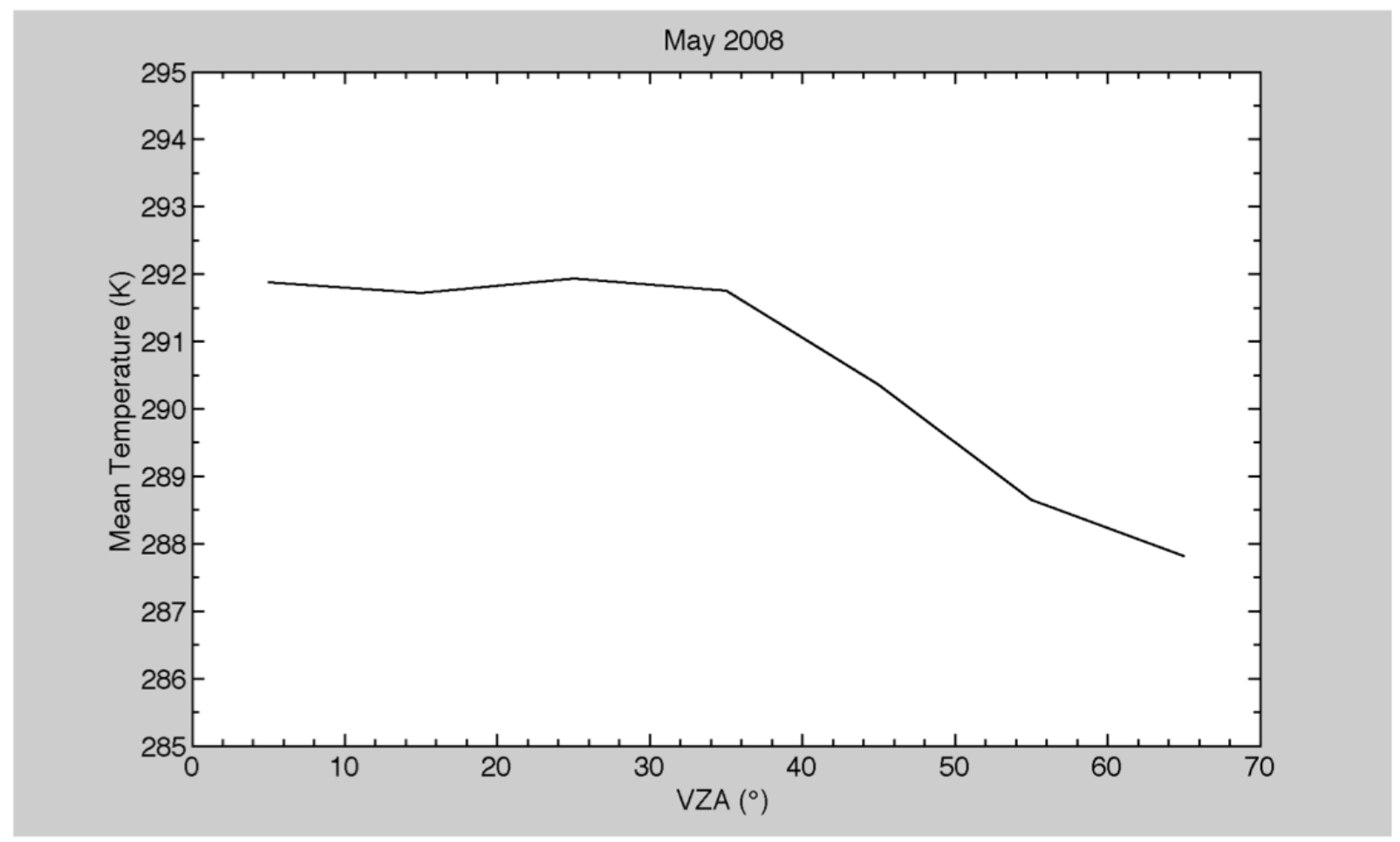

Figure 7. May 2008 11- $\mu \mathrm{m}$ BT from the region of study as a function of increasing VZA, i.e., limb darkening effect. 

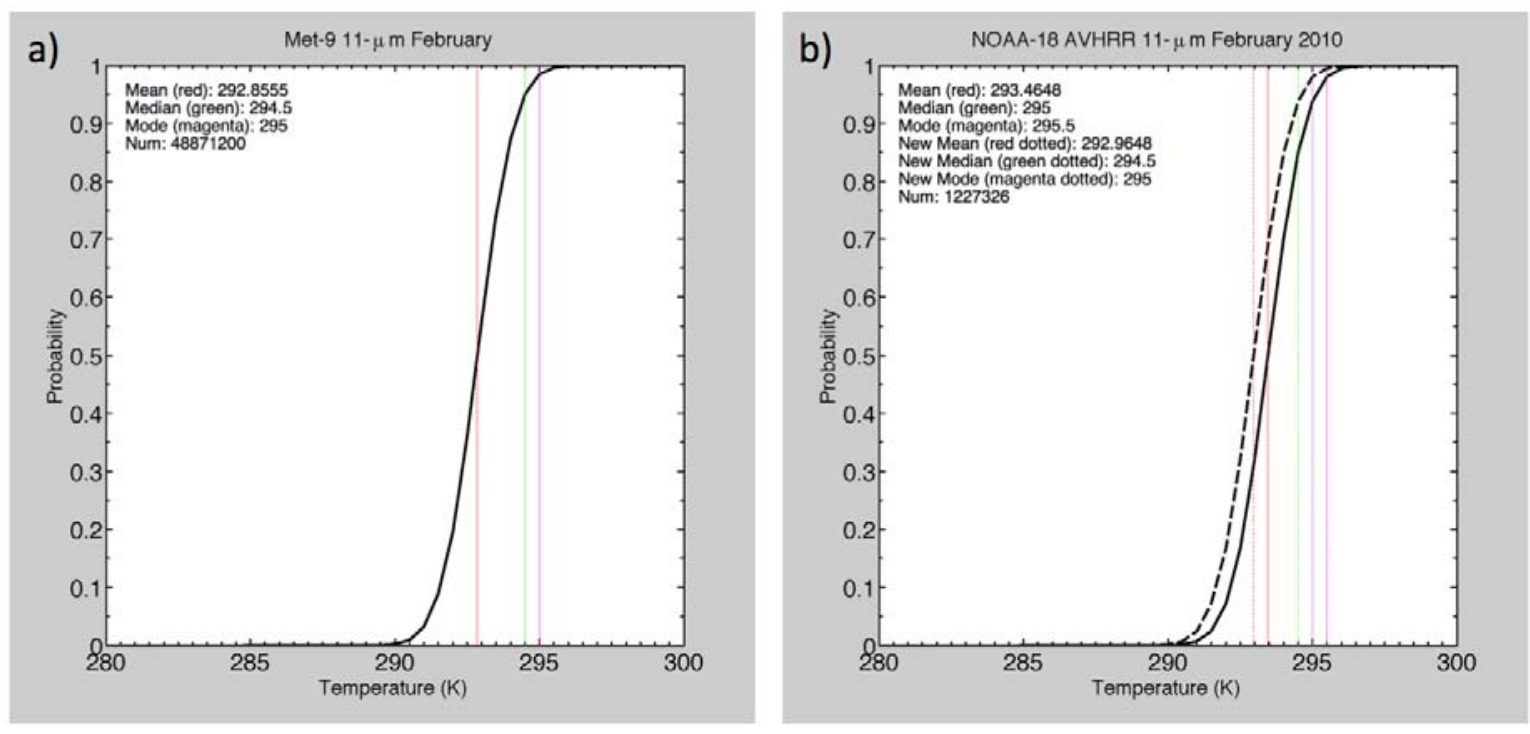

Figure 8. (a) Met-9 February 11- $\mu \mathrm{m}$ channel CDF IR model and (b) NOAA-18 AVHRR February 2010 11- $\mu$ m channel CDF. Solid lines indicate CDF and statistics before histogram matching calibration transfer; dashed lines are the CDF and statistics after the calibration transfer.
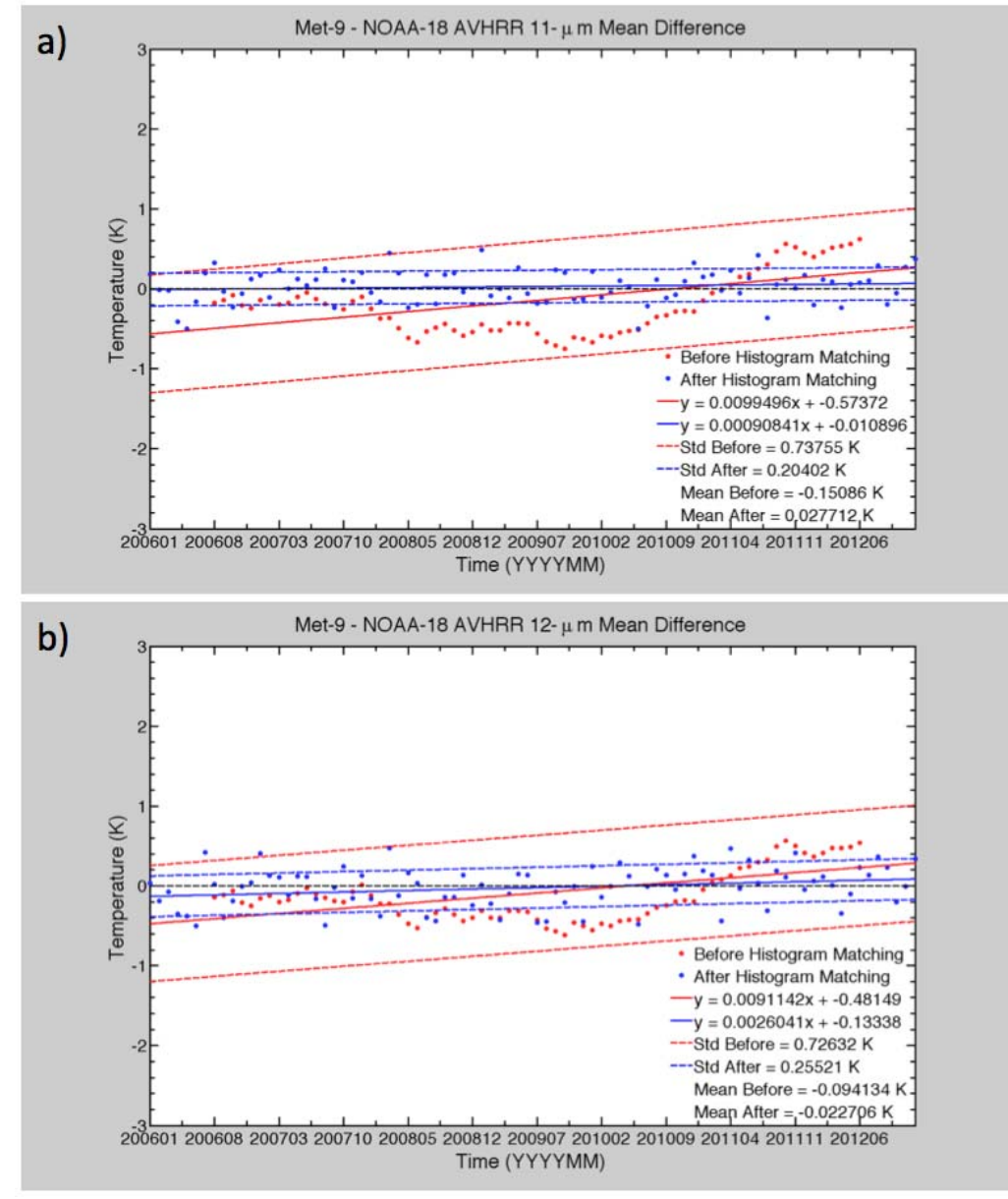

Figure 9. The Met-9-minus-AVHRR mean differences before and after applying the histogram matching calibration transfer for the (a) 11- and (b) 12- $\mu \mathrm{m}$ channels. A 12-month smoothing adjustment is applied to the before (red) points. 


\section{RESULTS AND DISCUSSION}

The histogram matching is performed for every month of the 2006-2012 NOAA-18 AVHRR record. Only months having an absolute mean difference between Met-9 and AVHRR in excess of $0.5 \mathrm{~K}$ are adjusted to match the IR model. The 12-month running mean AVHRR minus the site IR model BT differences are shown in Fig. 9. The monthly Met-9minus-AVHRR un-shifted model BT differences are smoothed using a 12-month running mean, as shown in Fig. 9a. Before matching, the mean differences are as large as $2 \mathrm{~K}$, the average mean difference is $-0.15 \mathrm{~K}$, and the standard deviation is $0.73 \mathrm{~K}$. After matching, by design the mean differences cannot exceed $0.5 \mathrm{~K}$, the average mean difference is $0.03 \mathrm{~K}$, and the standard deviation is $0.20 \mathrm{~K}$. Similarly, for the $12-\mu \mathrm{m}$ channel, the average mean difference improves form $-0.09 \mathrm{~K}$ to $0.02 \mathrm{~K}$, and the standard deviation falls from $0.73 \mathrm{~K}$ to $0.26 \mathrm{~K}$. In addition, the natural variability of the Namibian site, as shown initially in Fig. 3, is evident in the Met-9-minus-AVHRR model BT differences (Fig. 9 red dots). It is also apparent that the site natural variability is aliased into the AVHRR IR calibrated dataset. The magnitude of the site natural variability is probably also greater than the AVHRR IR correction that is required.

If the AVHRR BT values were perfectly stable, and the IR model was also perfect, then only the site natural variability would be observed in Fig. 9. This is not the true AVHRR calibration signal. If the site natural variability could be removed then the AVHRR calibration bias and drift could be inferred. If the AVHRR record were long enough, such that the natural variability did not bias it, then the mean record AVHRR BT bias could be determined. Removing the individual site natural variability remains the challenge of this method. A 12-month running average of meansubtracted AVHRR BT bias for 2006-2012 shows a natural variability pattern that is rather similar to that of the CERES all-sky TOA WN flux for the same time period (Fig. 10). Both datasets, having had their means subtracted out, show a similar transition from higher-to-lower bias near the beginning of 2011.

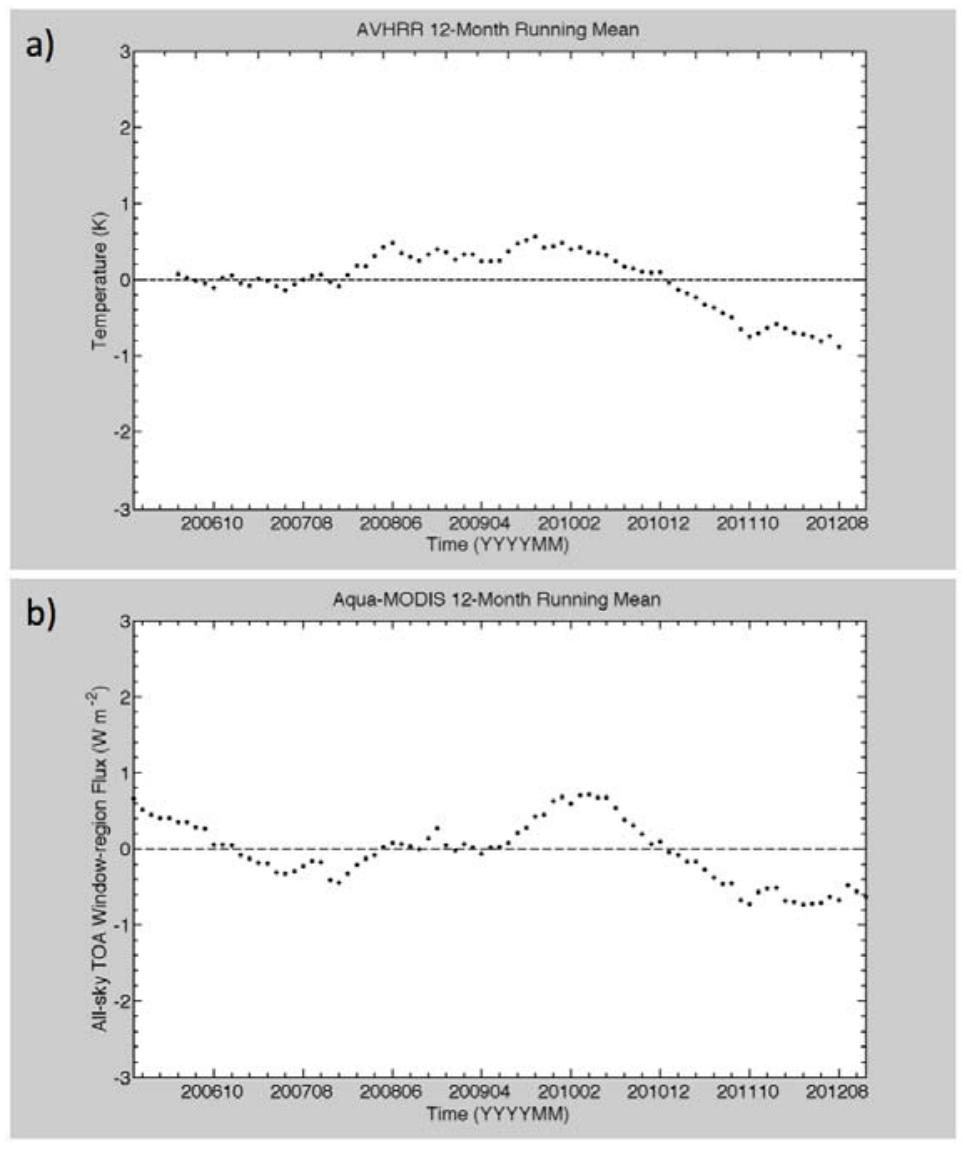

Figure 10. The (a) AVHRR 12-month running average, mean-subtracted BT and the (b) CERES 12-month running mean deseasonalized TOA WN flux from 200601 through 201212. 
To validate the successful implementation of the model, the lifetime BT difference is compared to monthly AVHRR and Met-9 ray-matched results. Ray-matching is method of comparison between two imagers in which biases are assessed for data points that match in, time, location, viewing angle, and azimuth angle. Figure 11a shows an example of an AVHRR and Met-9 11- $\mu \mathrm{m}$ channel ray-matched comparison. Figure 11b shows a series of ray-match biases before (red) and after (blue) the Met-9 deicing event of April 2008. Assuming that the results past April 2008 remain steady, as predicted by Fig. $4 \mathrm{a}$, the ray-matched mean bias of $-0.16 \mathrm{~K}$ is very close to the $-0.15-\mathrm{K}$ mean difference from the IR model.
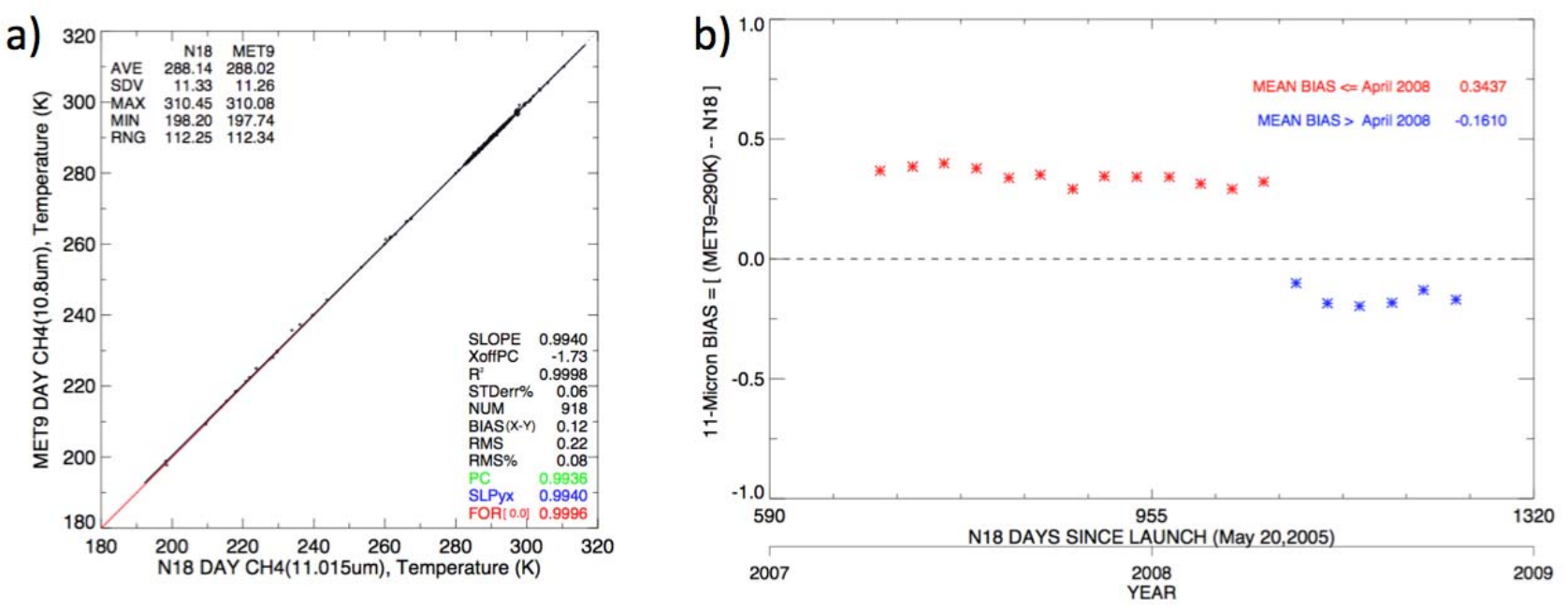

Figure 11. (a) Post-April 2008 ray-matched comparison of Met-9 and NOAA-18 AVHRR for the 11- $\mu$ m channel, and (b) timeline of the ray-match biases before (red) and after April (blue) 2008.

\section{CONCLUSIONS}

Well-calibrated satellite instrument measurements of the Earth's radiant energy are essential to the development of long-term remote-sensing-based climate data records. The Earth-observing community can benefit from such a record that would span a minimum of 30 years by making historical satellite calibrations consistent with those of today's imagers. To accomplish such a task, the IR calibration of the historical instruments must be traceable to an absolute standard. Several large, well-characterized warm and cold Earth targets have the potential of serving as these standards, which could provide a reference accuracy of within $0.5 \mathrm{~K}$.

A perfectly stable, invariant Earth target would be able to calibrate the historical satellite record using the method presented in this manuscript. Therefore, the greatest challenge is isolating and removing that natural variability from our chosen IR calibration sites. It might be necessary to evaluate several sequential AVHRR satellite records to isolate the natural variability. Otherwise the true calibration signal can be biased over the instrument lifetime. Natural variability, which is unique to each site owing to ENSO or similar climatological oscillations, can be sufficiently isolated from individual satellite bias using multi-satellite, multi-year NOAA AVHRR BT differences. Therefore, future work entails extending the BT difference analysis through previous sequential AVHRR instruments, while using several IR Earth targets simultaneously as validation of the site specific natural variability. Resolving these AVHRR differences for both warm and cold targets would allow for a BT-dependent bias correction, leading to a climate-quality IR data record.

\section{ACKNOWLEDGMENTS}

This research was supported by the NASA Modeling, Analysis, and Prediction Program and the NASA Satellite Calibration Interconsistency Program. 


\section{REFERENCES}

[1] Goldberg, M., Ohring, G., Butler, J., Cao, C., Datla, R., Doelling, D., Gärtner, V., Hewison, T., Iacovazzi, B., Kim, D., Kurino, T., Lafeuille, J., Minnis, P., Renaut, D., Schmetz, J., Tobin, D., Wang, L., Weng, F., Wu, X., Yu, F., Zhang, P., Zhu, T., "The Global Space-based Inter-Calibration System (GSICS)," Bull. Amer. Meteor. Soc. 92(4), 467-475 (2011).

[2] Hilton, F. et al., "Hyperspectral earth observations from IASI: four years of accomplishments," Bull. Amer. Meteor. Soc., doi: 10.1175/BAMS-D-11-00027.1 (2011).

[3] Minnis, P. and E. F. Harrison, "Diurnal variability of regional cloud and clear-sky radiative parameters derived from GOES data, Part III: November 1978 radiative parameters,” J. Clim. Appl. Meteor., 23, 1032-1052 (1984).

[4] Brooks, D. R., C. F. England, G. E. Hunt, and P. Minnis, "An intercomparison of Meteosat 1 and GOES 2 visible and infrared measurements," J. Atmos. Ocean. Technol., 1, 283-286 (1984).

[5] Minnis, P., "Viewing zenith angle dependence of cloudiness determined from coincident GOES East and GOES West data," J. Geophys. Res., 94, 2303-2320 (1989).

[6] Minnis, P., L. Nguyen, D. R. Doelling, D. F. Young, W. F. Miller, and D. P. Kratz, "Rapid calibration of operational and research meteorological satellite imagers, Part I: Evaluation of research satellite visible channels as references," J. Atmos. Ocean. Technol., 19, 1233-1249 (2002).

[7] Minnis, P., L. Nguyen, D. R. Doelling, D. F. Young, W. F. Miller, and D. P. Kratz, "Rapid calibration of operational and research meteorological satellite imagers, Part II: Comparison of infrared channels," J. Atmos. Ocean. Technol., 19, 1250-1266 (2002).

[8] Minnis, P., D. R. Doelling, L. Nguyen, W. F. Miller, and V. Chakrapani, "Assessment of the visible channel calibrations of the TRMM VIRS and MODIS on Aqua and Terra," J. Atmos. Ocean. Technol., 25, 385-400 (2008).

[9] Minnis, P., Q. Z. Trepte, S. Sun-Mack, Y. Chen, D. R. Doelling, D. F. Young, D. A. Spangenberg, W. F. Miller, B. A. Wielicki, R. R. Brown, S. C. Gibson, and E. B. Geier, "Cloud detection in non-polar regions for CERES using TRMM VIRS and Terra and Aqua MODIS data," IEEE Trans. Geosci. Remote Sens., 46, 3857-3884 (2008).

[10] Doelling, D. R., G. Hong, D. Morstad, R. Bhatt, A. Gopalan, and X. Xiong, "The characterization of deep convective cloud albedo as a calibration target using MODIS reflectance," Proc. SPIE 7862, 78620I; doi:10.1117/12.869577 (2011).

[11] Morstad, D. L., Doelling, D. R., Bhatt, R., and Scarino, B., "The CERES calibration strategy of the geostationary visible channels for CERES cloud and flux products," Proc. SPIE 8153, 815316-815316-13 (2011).

[12] Doelling, D. R., Morstad, D. L., Scarino, B. R., Bhatt, R., and Gopalan, A., "The characterization of deep convective clouds as an invariant calibration target and as a visible calibration technique," IEEE Transactions on Geoscience and Remote Sensing, 51, 1147-1159 (2013).

[13] Bhatt, R., D. R. Doelling, D. L. Morstad, B. R. Scarino, and A. Gopalan, "Desert-based absolute calibration of successive geostationary visible sensors using a daily exoatmospheric radiance model," IEEE Transactions on Geoscience and Remote Sensing, 51, 3670-3682 (2013).

[14] Heidinger, A. K., W. C. Straka, C. C. Molling, J. T. Sullivan, and X. Q. Wu, "Deriving and inter-sensor consistent calibration for the AVHRR solar reflectance data record," Int. J. Remote Sens., 31, 6493-6517 (2010).

[15] Skupin, J. et al., "SCIAMACHY solar irradiance observation in the spectral range from 240 to $2380 \mathrm{~nm}$," Adv. Space Res., 35, 370-375 (2005).

[16] Doelling, D. R., Lukashin, C., Minnis, P., Scarino, B., and Morstad, D., "Spectral reflectance corrections for satellite intercalibrations using SCIAMACHY data," IEEE Geosci. Remote Sens. Lett. 9, 119-123 (2012).

[17] Scarino, B., D. R. Doelling, D. L. Morstad, R. Bhatt, A. Gopalan, C. Lukashin, and P. Minnis, "Using SCIAMACHY to improve corrections for spectral band differences when transferring calibration between visible sensors," Proc. SPIE, 8510, Earth Observing Systems XVII, 85100Q; doi:10.1117/12.929767 (2012).

[18] Doelling, D. R., B. R. Scarino, D. Morstad, A. Gopalan, R. Bhatt, C. Lukashin, and P. Minnis, "The intercalibration of geostationary visible imagers using operational hyperspectral SCIAMACHY radiances," IEEE Transactions on Geoscience and Remote Sensing, 51, 1245-1254 (2013).

[19] Knapp, K. R., "Calibration assessment of ISCCP geostationary infrared observations using HIRS," J. Atmos. Oceanic Technol., 25, 183-195 (2008).

[20] Rossow, W. B., and R. A. Schiffer, “Advances in understanding clouds from ISCCP,” Bull. Amer. Meteor. Soc., 80, 2261-2287 (1999).

[21] Chen, R., C. Cao, and W. P. Menzel, "Intersatellite calibration of NOAA HIRS CO 2 channels for climate studies," J. Geophysical Research, 118, 5190-5203 (2013). 
[22] Wielicki, B. A., et al., "Evidence for large decadal variability in the tropical mean radiative energy budget," Science, 295, 841-844 (2002).

[23] Trenberth, K. E., "Changes in tropical clouds and radiation," Science, 296, 2095 (2002).

[24] NOAA Earth System Research Laboratory: Physical Science Division, "Climate timeseries: AMO (Atlantic Multidecadal Oscillation) index," http://www.esrl.noaa.gov/psd/data/timeseries/AMO/ (2014).

[25] Rakwatin, P., W. Takeuchi, and Y. Yasuoka, "Stripe noise reduction in MODIS data by combining histogram matching with facet filter," IEEE Trans. Geosic. Remote Sens., 45, 1844-1856 (2007).

[26] Simpson, J. J., J. I. Gobat, and R. Frouin, "Improved destriping of GOES images using finite impulse response filter," Remote Sens. Environ., 52, 15-35 (1995).

[27] Simpson, J. J., J. R. Stitt, and D. M. Leath, "Improved finite impulse response filters for enhanced destriping of geostationary satellite data," Remote Sens. Environ., 66, 235-249 (1998).

[28]Horn, B. K. P., and R. J. Woodham, "Destriping Landsat MSS images by histogram modifications," Comput. Graph. Image Process, 10, 69-83 (1979).

[29] Weinreb, M. P., R. Xie, J. H. Lienesch, and D. S. Crosby, "Removing stripes in GOES images by matching empirical distribution functions," NOAA Technical Memorandum, QC 879.5, .U43, no. 26 (1989).

[30] Shen, H. and L. Zhang, "A MAP-based algorithm of destriping and inpainting of remotely sensed images," IEE Trans. Geosci. Remote Sens., 47, 1492-1502 (2009).

[31] Tokuno, M. and S. Kurihara, "Intercalibrations of GMS-5 IR channels and NOAA-14 AVHRR Channels 4 and 5," Adv. Space Res., 23, 1349-1356 (1999).

[32] Wu, X., M. Weinreb, I. -L. Chang, D. Crosby, C. Dean, F. Sun, and D. Han, "Calibration of GOES imager visible channels," Proc. IGARSS IEEE International; doi:10.1109/IGARSS.2005.1526580 (2005).

[33] Yu, F., X. Wu, M. K. Rama Varma Raja, Y. Li, L. Wang, and M. Goldberg, "Diurnal and scan angle variations in the calibration of GOES imager infrared channels," IEE Trans. Geosci. Remote Sens., 51, 671-683 (2013). 